\title{
PENENTUAN TOTAL POLIFENOL EKSTRAK ETANOL KULIT KECAPI (Sandoricum koetjape) DARI LAMASI KABUPATEN LUWU
}

\author{
Santi Sinala ${ }^{1}$, Minati $^{2}$, Alfrida Monica Salasa ${ }^{3}$ \\ 1,3 Jurusan Farmasi Poltekkes Kemenkes Makassar \\ ${ }^{2}$ Stikes Bhakti Pertiwi Luwu Raya Palopo
}

*) Coresponden author : santisinala@poltekkes-mks.ac.id, Hp. 085255918123

\section{https://doi.org/10.32382/mf.v14i2.594}

Penelitian ini bertujuan untuk menentukan kadar total polifenol dari ekstrak etanol kulit kecapi (Sandoricum koetjape) dari Lamasi Kabupaten Luwu. Penentuan total polifenol dilakukan menggunakan spektrofotometer UV Vis pada panjang gelombang $656 \mathrm{~nm}$ dengan menggunakan pereaksi FolinCiocalteau (1:1) dan $\mathrm{Na}_{2} \mathrm{CO}_{3}$ 7,5\%. Hasil pengukuran berdasarkan dari absorban intensitas warna yang dikalibrasi dalam kurva baku asam gallat. Analis data menggunakan persamaan kurva baku y $=0,061 \mathrm{x}-$ 0,036. Diperoleh total polifenol pada ekstrak etanol kulit kecapi (Sandoricum koetjape) yaitu sebesar $5,74 \%$.

Kata kunci : Total polifenol, ekstrak kulit kecapi (Sandoricum koetjape), spektrofotometer uv-vis.

\section{PENDAHULUAN}

Indonesia kaya akan tumbuhan yang

beraneka jenis. Tumbuh-tumbuhan ini mengandung senyawa metabolit sekunder yang dapat dijadikan sebagai bahan dasar obat yang digunakan dalam usaha preventif dan kuratif pada penyakit. Melihat potensi pengobatan dari bahan-bahan alam, masyarakat kembali ke alam dalam penggunaan tumbuh-tumbuhan alami sebagai obat baik dalam bentuk rebusan maupun dalam bentuk ekstrak yang lain yang telah dikemas baik. Hal ini untuk membiasakan hidup dengan menghindari bahan-bahan kimia sintesis (Kardinan dan Kusuma, 2004). Menurut beberapa penelitian, obat-obat tradisional banyak digunakan karena memiliki efek samping yang minimal, apalagi jika berbicara masalah harga, maka harga obat-obat tradisional lebih terjangkau disbanding dengan obat-obat sintetis di pasaran.

Bagian dari obat tradisional yang bisa dimanfaatkan adalah akar, rimpang, kulit, batang, buah, daun, dan bunga (Chutichudet dan Chutichudet, 2009). Buah kecapi (Sandoricum koetjape) dikenal juga dengan sebutan buah sentul, buah ini diperkirakan berasal dari indocina dan semenanjung Malaya berabadabad yang silam. Buah kecapi banyak ditemukan di pasar tradisonal dengan harga relatif murah. Buah kecapi biasanya digunakan sebagai bahan pencita rasa dengan memberikan rasa asam pada masakan. Biasanya buah kecapi dikonsumsi dalam bentuk segar. Selain itu dapat diolah menjadi selai manisan, sirup, minuman beralkohol yang difermentasi bersama beras.
Selain itu dapat dibuat permen yang berasal dari buah muda (Morton, 1987).

Buah kecapi mengandung antioksidan seperti beta karoten dan subtansi bioaktif polifenol dalam jumlah besar, yaitu 6,5 millimbos per 100 gr buah segar. Zat tersebut berperan sebagai anti-oksidatif serta anti karsinogenik yang berkhasiat untuk mencegah terjadinya penyakit kanker (Morton, 1987). Penggunaan secara tradisional oleh masyarakat dimana daunnya dapat mengurangi gejala sakit perut dan demam. Kulit batang yang diserbukkan dapat mengobati penyakit cacing gelang. Penggunaan akarnya sebagai anti diare (Idris, 1998). Khasiat buah kecapi diatas disebabkan karena mengandung senyawa polifenol.

Senyawa polifenol adalah kelompok zat kimia yang ditemukan pada tumbuhan, zat ini memiliki tanda khas yakni memiliki banyak gugus fenol dalam molekulnya.Polifenol merupakan komponen yang bertanggung jawab terhadap aktivitas antioksidan dalam buah dan sayuran (Hattenschwiler dan vitousek,2000). Melihat adanya kandungan senyawa polifenol pada kulit buah kecapi maka akan ditentukan kadar total polifenol di dalam ekstrak etanol kulit kecapi.

Rumusan masalah yang timbul adalah berapa kadar total polifenol ekstrak etanol kulit kecapi (Sandoricum koetjape) dari daerah Lamasi Kabupaten Luwu. Sedangkan tujuan dari penelitian untuk menentukan kadar total polifenol ekstrak kulit buah kecapi (Sandoricum koetjape) dari daerah Lamasi Kabupaten Luwu 


\section{METODE}

Jenis Penelitian

Jenis penelitian eksperimental

laboratorium. Penelitian dilaksanakan pada bulan April 2018 di Laboratorium Biologi Farmasi dan Laboratorium Kimia Jurusan Farmasi Poltekkes Kemenkes Makassar.

\section{Alat dan bahan}

Alat yang digunakan pada penelitian ini antara lain rotavapor, alat soklet, alat alat gelas, spektrotofotometer. Sedangkan bahanbahan yang digunakan dalam penelitian ini yaitu kulit buah kecapi, etanol 96\%, FolinCiocalteau, natrium karbonat $\left(\mathrm{Na}_{2} \mathrm{CO}_{3}\right)$ dan asam gallat.

\section{Langkah-langkah Penelitian Penyiapan simplisia}

Sampel diperoleh dari daerah Lamasi Kabupaten Luwu. berat sampel basah 1100 gram setelah disortasi basah dan kering dipotong-potong kecil kemudian dikeringkan dengan cara diangin-anginkan, setelah kering lalu dihaluskan kemudian ditimbang sebagai berat kering 101,07gram, kemudian diekstraksi dengan cara sokletasi. Hasil ekstraksi diuapkan hingga diperoleh ekstrak kental.

\section{Pengukuran Total Polifenol Ekstrak Etanol Kulit Buah Kecapi}

Penetapan Panjang Gelombang Maksimum

Dibuat larutan stok asam gallat sebanyak 500 ppm. Dari larutan stok tersebut dibuat pengenceran asam gallat standar dengan konsentrasi $4 \mu \mathrm{g} / \mathrm{ml}$. kemudian ditambahkan reagenFolin-Ciocalteau (1:1) dan dikocok. Setelah didiamkan selama 3 menit, masingmasing konsentrasi ditambahkan larutan $\mathrm{Na}_{2} \mathrm{CO}_{3} \quad 7,5 \%$ (1:1) dan dihomogenkan, kemudian dicukupkan volumenya hingga $10 \mathrm{ml}$ dengan menggunakan Air suling. Kemudian larutan diukur absorbansinya pada panjang gelombang 400-800 nm. Selanjutnya dibuat kurva baku asam gallat. Diperoleh panjang gelombang maksimum $656 \mathrm{~nm}$.

\section{Pembuatan Kurva baku Asam Gallat Standar}

Dibuat seri larutan asam gallat dengan konsentrasi $2 \mu \mathrm{g} / \mathrm{ml}, 4 \mu \mathrm{g} / \mathrm{ml}, 6 \mu \mathrm{g} / \mathrm{ml}, 8 \mu \mathrm{g} / \mathrm{ml}$, $10 \mu \mathrm{g} / \mathrm{ml}$. kemudian masing-masing ditambahkan $200 \mu \mathrm{L}$ Folin-Ciocalteau (1:1) setelah didiamkan selama 3 menit, masingmasing konsentrasi ditambahkan larutan $200 \mu \mathrm{L}$ $\mathrm{Na}_{2} \mathrm{CO}_{3} \quad 7,5 \% \quad(1: 1)$ dan dihomogenkan kemudian diukur serapannya pada panjang gelombang maksimum.

\section{Penetapan Kandungan Total Fenol dari Ekstrak Etanol kulit buah kecapi}

Kandungan total fenol ditentukan menggunakan metode McDonald yang telah dimodifikasi. Dibuat pengenceran sampel ekstrak etanol kulit buah kecapi dalam pelarut etanol 96\% dengan konsentrasi 1000 ppm. Diambil $1 \mathrm{ml}$ dari pengenceran ekstrak, kemudian dimasukkan kedalam labu ukur $10 \mathrm{ml}$ dan ditambahkan reagen $200 \mu \mathrm{L}$ FolinCiocalteau (1:1) dan dikocok. Setelah didiamkan selama 3 menit, masing-masing konsentrasi ditambah larutan $\mathrm{Na}_{2} \mathrm{CO}_{3} 200 \mu \mathrm{L}$ 7,5\% (1:1) dan dikocok homogen, kemudian masing-masing dicukupkan volumenya hingga 10 ml dengan menggunakan Air suling Kemudian larutan diukur absorbansinya pada panjang gelombang $656 \mathrm{~nm}$.

\section{Analisis Data}

Kadar polifenol, dihitung berdasarkan kurva kalibrasi hasil pembacaan dari alat spektrofotometer UV-Vis dan persamaan regresi linear dengan menggunakan hukum LambertBeer seperti pada persamaan :

$$
\text { Dimana: } \quad \begin{aligned}
y=b x & +a \\
\mathrm{y} & =\text { Absorbansi } \\
\mathrm{x} & =\text { Konsentrasi (C) mg.L } \\
\mathrm{b} & =\text { Slope (kemiringan) } \\
\mathrm{a} & =\text { Intersep }
\end{aligned}
$$

HASIL

Hasil penelitian ini memperoleh data dimana berat rendamen yang diperoleh adalah $12.6 \%$. Sedangkan nilai total polifenol dari ekstrak etanol kecapi adalah sebesar 5,74\%.

\section{PEMBAHASAN}

Pada penelitian ini dilakukan penentuan kadar senyawa polifenol pada kulit buah kecapi (Sandoricum koetjape) yang berasal dari Daerah Lamasi Kabupaten Luwu dengan menggunakan alat spektrofotometer uvvis. Buah kecapi (sandoricum koetjape) merupakan buah yang sering dikonsumsi di masyarakat biasanya yang dikomsumsi hanyalah bijinya sementara kulit buahnya dibuang menjadi limbah. Sebelum melakukan penelitian, kulit kecapi terlebih dahulu dibuat dalam bentuk simplisia lalu kemudian diekstraksi dengan mengunakan metode sokletasi. Pemilihan metode sokletasi dikarenakan simplisia dari kulit kecapi memiliki konsistensi yang keras. 
Ekstrak etanol kulit kecapi mengandung senyawa fenol, diperoleh kadar polifenol dalam ekstrak 5,74\%. Senyawa fenol merupakan suatu senyawa yang mengandung gugus hidroksil $(-\mathrm{OH})$ yang terikat langsung pada gugus cincin hidrokarbon aromatik. Klasifikasi senyawa fenol yang terkandung dalam tumbuhan yaitu fenol sederhana, benzoquinone, asam fenolat, asetofenon, naftokuinon, xanton, asam hidroksi sinamad, flavonoid, lignan, dan tanin. Senyawa fenol alami yang bersifat antioksidan dapat diklasifikasikan dalam 2 (dua) kelompok, yaitu kelompok lipofilik dan hidrofilik (diantaranya senyawa fenol). Aktivitas antioksidan dari senyawa fenol terbentuk karena kemampuan senyawa fenol membentuk ion fenoksida yang dapat membersihkan satu elektronnya kepada radikal bebas. Pada umumnya, antioksidan senyawa fenol dapat bereaksi dengan radikal bebas membentuk ROOH dan sebuah senyawa fenol radikal yang relatif tidak reaktif, Adanya antioksidan diyakini memiliki khasiat meningkatkan kemampuan anti-inflamasi dan kekebalan tubuh.

Sebagian besar polifenol adalah antioksidan sehingga mampu menetralkan radikal bebas yang memiliki efek merusak terhadap sel-sel dan jaringan tubuh, radikal bebas sering dikaitkan sebagai penyebab kerusakan sel yang berhubungan dengan penuaan. Sebagai antioksidan kuat, polifenol mampu memperlambat proses penuaan, Biasanya polifenol yang sering ditemukan dalam tanaman efektif membantu menurunkan berat badan dan senyawa ini merangsang tubuh untuk membakar lebih banyak lemak dan kalori.

Sebagai simpulan penelitian, kadar polifenol total dalam ekstrak etanol kulit kecapi yaitu sebesar $5,74 \%$.

\section{KESIMPULAN}

Kadar total senyawapolifenol yang terdapat pada ekstrak etanol kulit kecapi adalah $5,74 \%$

\section{SARAN}

Dari adanya data total polifenol disarankan dilakukan uji efek farmakologi dan mikrobiologi.

DAFTAR PUSTAKA

Afifah,Riski.2012. MetodeMaserasi.(Online) http://ekstraksitanamanobat.blogspot.c om. Diaksestanggal 18 April 2014

Harbone, J.B,1987. Metode fitokimia: penuntun Cara Moderen menganalisis
Tumbuhan Terbitan keduan. Bandung: TTB

Anonim. 1994. Mengenal Tanaman Langka Indonesia. Penebar Swadaya, Jakarta.

Anonim. 2011. Prinsip Ekstraksi dengan Cara Sokletasi

.(Online).http://nurfaisyah.web.id. Diakses tanggal 26 April 2013.

Basset, J. 1994. Kimia Analisis Kuantitatif Anorganik. EGC. Jakarta.

Beran, J.A.1996. Chemistry in The Laboratory.John Willey \& Sons.

Chutichudet, B. And P.Chutichudet. 2009. Control of skin colour and polyphenol oxidase activity in kecapi fruit by diping in organic acid solutin. Paksitan journal of Biological Sciences 12(11):852-858.

Hattenschwiler, S danvitousek, P.M. 2000.The Role Of Polyphenols intemestrialEcosystem Nutrient Cycling.

Hamdani.2014. Maserasi

(Online).http://catatankimia.com. Diak sestanggal 18 April2014.

Idris, S. 1998. Sandoricum Cav. In Sosef, M.S.M., L.T. Hong, and S. Prawirohatmodjo (eds.). Timber trees: lesser-known timbers. Prosea, Bogor.

Irawan, Bambang 2010. Peningkatan mutu kutib buah kecapi dengan ekstraksi dan destilasi pada berbagai komposisi pelarut. Semarang: universitas Negeri Gorontalo.

Kardinan, dkk.2004, kecapi: Berwarna kuning untuk industri minuman, Jakarta

Morton, J. 1987. Santol. In Morton, J.F. (ed.). Fruits of warm climates.Miami.

Miller, J.N dan miller, j.c 2000. Statistika and Chemometrics for analytical ChemistrY,.

Verheij, E.W.M. dan R.E. Coronel (eds.). 1997. SumberDayaNabati Asia Tenggara 2.Buah-buahan yang dapat dimakan. PROSEA-Gramedia. Jakarta

Rahmandunggio. 2102. Soxhletasi. (Online), Diakses tanggal 18 April 2014.

Underwoord, A, L, 1990. Analisis Kimia Kiantitatif Edisi ke Enam. Erlangga. 
Tabel 1.Data Hasil Ekstraksi menggunakan etanol

\begin{tabular}{ccc}
\hline Simplisia & Berat kering & Ekstrak kental \\
\hline $\begin{array}{c}\text { Kulit buah kecapi } \\
\text { (Sandoricum koetjape) }\end{array}$ & 101,07 gram & 12,7477 gram \\
\hline
\end{tabular}

Tabel 2.Absorban standar asam gallat

\begin{tabular}{cc}
\hline Konsentrasi $\mu \mathrm{g} / \mathrm{ml}$ & Absorban \\
\hline 2 & 0,10638 \\
4 & 0,20662 \\
6 & 0,30372 \\
8 & 0,42936 \\
10 & 0,60596 \\
\hline
\end{tabular}

Tabel 3.Penetapan Kandungan Total Fenol dari Ekstrak Etanol Kulit Buah Kecapi

\begin{tabular}{ccc}
\hline Berat ekstrak $($ gram $)$ & Konsentrasi $\mu \mathrm{g} / \mathrm{ml}$ & Absorban \\
\hline 0,0565 & 100 & 0,35482 \\
0,0534 & 100 & 0,34508 \\
0,0523 & 100 & 0,32921 \\
\hline
\end{tabular}




\section{MEDIA FARMASI}

POLITEKNIK KESEHATAN MAKASSAR

Penasehat

Penanggung Jawab

Dewan Redaksi

Ketua

Anggota

Mitra Bestari

Alamat Redaksi
: Direktur Politeknik Kesehatan Kemenkes Makassar

: Ketua Jurusan Farmasi Politeknik Kesehatan

Kemenkes Makassar

: $\quad$ Santi Sinala, S,Si, M.Si, Apt

: Hendra Stevani, S.Si, M.Kes, Apt

Sisilia Teresia Rosmala Dewi, S.Si, M.Kes, Apt

Muli Sukmawaty, S.Farm, Apt

Muhammad Riswan, S.Kom

: $\quad$ Dr. Islamudin Ahmad, M.Si,Apt (Universitas Mulawarman)

DR. Rusli, Sp.FRS, Apt

DR. Hj. Nurisyah, M.Si, Apt (Poltekkes Makassar)

DR. Sesilia Rante Pakadang, M.Si, Apt (Poltekkes Makassar)

DR. H. Asyhari Asyikin, S.Farm, M.Kes (Poltekkes Makassar)

: Jurusan Farmasi

Politeknik Kesehatan Kementerian Kesehatan Makassar

J1. Baji Gau No.10 Makassar

Telp. 0411-854021, 830883 Fax. 0411-830883

Kode pos 90134

Website :

http://journal.poltekkes-mks.ac.id/ojs2/index.php/mediafarmasi/index 


\section{EDITORIAL}

Pembaca yang budiman, ucapan syukur Alhamdulillah kami panjatkan ke hadirat Tuhan Yang Maha Kuasa karena berkat rahmat dan anugerahNya sehingga penerbitan Vol. XIV No.2, Oktober 2018 MEDIA FARMASI POLITEKNIK KESEHATAN MAKASSAR dapat terlaksana dan telah mendapat legalitas sebagai media resmi dari Lembaga Ilmu Pengetahuan Indonesia (LIPI) dengan nomor penerbitan pISSN No. 0216-2083 dan e-ISSN No. 2622-0962.

Media Farmasi Politeknik Kesehatan Makassar merupakan suatu wadah dalam menampung aspirasi ilmiah sehingga dapat menggugah motivasi dan inovasi dari dosen di lingkup Jurusan Farmasi Politeknik Kesehatan Makassar serta artikel dari simpatisan untuk melakukan kajian ilmiah.

Media Farmasi Politeknik Kesehatan Makassar diterbitkan 2 kali dalam setahun yaitu pada bulan April dan Oktober. Sebagai majalah ilmiah, Media Farmasi mengembangkan misi dalam memajukan ilmu pengetahuan dan teknologi kesehatan khususnya di bidang farmasi

Akhirnya redaksi sangat berharap bahwa semua artikel yang disajikan dalam edisi ini dapat memberi apresiasi keilmuan di bidang kesehatan bagi kita semua. Oleh karena itu kritikan dan saran sangat kami harapkan demi kesempurnaan edisi-edisi selanjutnya.

Selamat membaca

Makassar, Oktober 2018

Redaksi 


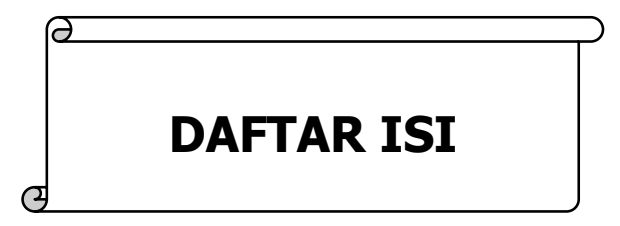

Pengaruh Pemberian Ekstrak Etanol Daun Afrika (Vernonia amygdalina

Del.) terhadap Kadar Asam Urat Darah Mencit Jantan (Mus musculus)

Jumain, Asmawati, Rini Karnita

Efektivitas Pemberian Rebusan Daun Pandan Wangi (Pandanus

Amaryllifolius Roxb.) terhadap Penurunan Kadar Glukosa Darah

Mencit (Mus musculus)

Amran Nur, Desi Reski Fajar, Musdalifah

Uji Efek Analgetik Infusa Jahe (Zingiber officinale Roscoe) terhadap Hewan Uji Mencit Jantan (Mus musculus)

Sisilia T. Rosmala Dewi, Hiany Salim.

Pengaruh Usia dan Tingkat Pendidikan terhadap Pemahaman Pasien

Setelah Pelayanan Informasi Obat di Puskesmas Makale Kabupaten

Tana Toraja Tahun 2018

Estherina Allo Payung, Septyani Mambela

Uji Daya Hambat Antibiotika Terhadap Bakteri Penyebab Infeksi

Saluran Kemih Di Rumah Sakit Salewangang Maros

Andi Dian Aulia Saudi, Rusdy

Uji Aktivitas Ekstrak Buah Pare (Momordica charantia L) terhadap Pertumbuhan Propionibacterium acnes

Dwi Rachmawaty Daswi, Asmawati

Analisis Kandungan Merkuri (Hg) pada Sediaan Krim Pemutih yang Beredar di Pasaran Kota Makassar dengan Menggunakan Metode Spektrofotometri Serapan Atom

Dedy Ma'ruf, Andi Asmawati, Ririn Muliana

Penentuan Total Polifenol Ekstrak Etanol Kulit Kecapi (Sandoricum koetjape) dari Lamasi Kabupaten Luwu

Santi Sinala, Minati, Alfrida Monica Salasa

Uji Potensi Antimikroba Hasil Fraksinasi Ekstrak Daun Kecombrang (Etlingera elatior) terhadap Candida albicans Penyebab Keputihan Pada Ibu Hamil

St. Ratnah, Alfrida Monica Salasa, H. Ismail Ibrahim 
Efek Konseling terhadap Tingkat Pengetahuan Ibu pada Terapi

Diare Balita

Khaerani, Surya Ningsi, Andi Try Resti Fauziah Sahib

Uji Daya Hambat Daun Tammate (Lannea coromandelica) terhadap

Bakteri Propionibacterium acnes dan Escherichia coli

Nurlaela, Abd.Karim, Taufiq Dalming

Efektivitas Ekstrak Air Buah Belimbing Wuluh (Averrhoa bilimbi)

Terhadap Pertumbuhan Propionibacterium acnes

Arisanty, Rara Puspa Dewi

Aktivitas Perasan Biji Pinang (Areca catechu L.) terhadap Pertumbuhan

Streptococcus mutans

Ikke Nurjanna, Hendra Stevani, Ratnasari Dewi

Evaluasi Tingkat Kepuasaan Pasien terhadap Pelayanan Kefarmasin di Depo IGD

Rumah Sakit TK II Pelamonia Makassar

Rahmawati, Desi Reski Fajar, Ira Widya Sari

78

Analisis Lama Waktu Tunggu Pelayanan Resep di Apotek BPJS

Rawat Jalan Rumah Sakit Pelamonia

Veronika Dampung, Ita Purnama Sari, Citra Rahayu, Rusli 